\title{
Intelligent Machining of Shape Memory Alloys
}

\author{
Kapil Gupta ${ }^{*}$ \\ 1 Department of Mechanical and Industrial Engineering Technology, University of Johannesburg, \\ Doornfontein-2028, Johannesburg, South Africa \\ * Corresponding author's email: kgupta@uj.ac.za
}

\begin{abstract}
Shape memory alloys are important biomaterials but difficult-to-machine (DTM). Their machining needs to be done using intelligent techniques to obtain a better machinability. Hybrid optimization is one of such techniques which can perform modeling and optimization of machining parameters for the best values of machinability indicators. Wire electric discharge machining (WEDM) of shape memory alloy has been found as a prominent alternate to the conventional machining techniques; however it needs the assistance of intelligent techniques to machine such materials to obtain the optimum values of machinability indicators. In this paper, WEDM of shape memory alloy $\mathrm{Ni}_{55.8} \mathrm{Ti}$ was reported. WEDM was carried out by varying four process parameters i.e. servo voltage SV, pulse-on time $\mathrm{P}_{\text {on }}$, pulse-off time $\mathrm{P}_{\text {off }}$, and wire feed rate WF using Taguchi $\mathrm{L}_{16}$ robust design of experiment technique. A hybrid optimization technique TOPSIS-Fuzzy-PSO has been successfully used to optimize these parameters (SV-50V; $\mathrm{P}_{\text {on }}-1 \mu \mathrm{s} ; \mathrm{P}_{\text {off }}-17 \mu \mathrm{s} ; \mathrm{WF}-4 \mathrm{~m} / \mathrm{min}$ ) for the best possible values of material removal rate (MRR) $-0.049 \mathrm{~g} / \mathrm{min}$, maximum roughness $-11.45 \mu \mathrm{m}$, and recast layer $-22.10 \mu \mathrm{m}$ simultaneously.
\end{abstract}

Keywords: optimization, shape memory alloy, TOPSIS-Fuzzy, WEDM.

\section{INTRODUCTION}

Shape memory alloys (SMAs) are smart materials that possess special characteristics of superelasticity, shape memory effect, and biocompatibility etc. which make them prime candidate materials for biomedical, precision and scientific applications. The NiTi type shape memory alloy is preferably used for biomedical applications and hence processed by various manufacturing techniques (machining is one of them) for the production of biomedical parts, instruments, and equipment [1]. $\mathrm{Ni}_{55.8} \mathrm{Ti}$ is a Ni-rich nickel titanium alloy and used in orthodontics, medical instrument, dental and orthopedic implants $[2 \div 3]$. However, it is a difficult-to-machine (DTM) material and its machinability is poor specially in the case of conventional machining. Excessive burr formation, higher strain hardening, high chemical reactivity, and severe tool wear etc. are some of the common problems. It compels to explore advanced machining techniques for machinability enhancement of this alloy [4].
Wire electric discharge machining (WireEDM or WEDM) is a thermal type advanced machining process that works on the principle of thermoelectric erosion, where the machining is done in the form of material removal due to the occurrence of a spark between a travelling wire electrode (cathode) and workpiece electrode (anode) [5]. This process has a previous track record to precisely machine DTM materials [6]. Taking this into consideration, WEDM has been used to machine $\mathrm{Ni}_{55.8} \mathrm{Ti}$ in the present work.

Modelling and computation of optimum process parameters is an essential requirement in machining operations in order to obtain high quality parts with high productivity. Optimum parameters, as regards to the specific application requirements for a particular material are important to be known. MRR, SR, cutting rate, microhardness, recast layer thickness, and dimensional error etc. are some of the major responses or machinability indicators which measure the success of any machining process. 
There are many statistical techniques available for optimization, but they suffer from certain inherent limitations, and commonly they all cannot effectively solve multi criteria decision making (MCDM) problems for contradictory responses [7]. Soft computing or evolutionary techniques such as NN, Fuzzy, TOPSIS, GA, and ANFIS etc. have been used recently to solve these problems.

Particle Swarm Optimization (PSO) is nature-inspired meta-heuristics technique for the solution of optimization problems. It has number of individuals known as particles, which learned from the movement of itself and the other particles of the swarms. The individual best is known as particle best (Pbest) and overall best is known as global best solution (Gbest). Every particle of the swarm remembers its own best and its current position and by the help of this data the best solution i.e. Gbest is found out [8]. The technique of order of preference by similarity of ideal solution (TOPSIS) is a technique to solve multi-objective problems. The integration of TOPSIS-Fuzzy provides a common performance index. TOPSIS is used for the normalization of data; however Fuzzy is further implemented to investigate the performance index by if-then statements. The review of literature on the effective use of these techniques in machining area is given below.

There has been a track record of successfully employing hybrid multi-criteria decision-making techniques for the WEDM type machining process $[9 \div 16]$. Response surface methodology and grey-Fuzzy algorithm based multi-response optimization of the WEDM parameters was done by Choudhuri et al. [9] for machining of stainless steel 316. They found significant improvement in results and achieved best values of responses such as $3.10 \mu \mathrm{m}$ average roughness, $4.701 \mathrm{~mm}^{3} /$ min material removal rate, and $16.749 \mathrm{~kg}$ wire consumption. Caydas et al. [10] developed adaptive neuro-fuzzy inference system (ANFIS) model for modeling and optimization of the WEDM process parameters. They successfully minimized surface roughness and white layer thickness produced after WEDM of AIDI D5 tool steel. Singh et al. [11] reported multiobjective optimization of wire-electro discharge machining of A15083/ B4C composite by Taguchi and Fuzzy based hybrid approach. The 2.8 to $4.5 \%$ errors have been investigated during validation experiment conducted after WEDM machining of composite at optimum parameters. Majumder and Maity [12] used MOORA-Fuzzy hybrid technique for WEDM parameter optimization and obtained significant improvement in surface quality and microhardness while machining nitinol shape memory alloy using WEDM. They reported 10$66 \%$ improvement in surface finish after machining at optimum WEDM parameters. Mukherjee et al. [13] highlighted the superiority of biogeography-based optimization technique for optimization of the WEDM parameters to achieve increment in process productivity and part surface quality. The nondominated sorting genetic algorithm integrated with Taguchi was employed by Magabe et al. [14] to improve the machinability of the WEDM process for $\mathrm{Ni}_{55.8} \mathrm{Ti}$ shape memory alloy. Mean roughness depth of $6.2 \mu \mathrm{m}$ and 0.021 $\mathrm{g} / \mathrm{min}$ material removal rate have been achieved after machining at optimum parameters produced by hybrid optimization technique. In an another important study, El-Bahloul [15] successfully improved process performance and stainless steel 304 part quality using response surface technique integrated Fuzzy approach. The research work reported by Tzeng et al. [16] highlights the effectiveness of back-propagation neural network (BPNN), a genetic algorithm (GA), and response surface methodology (RSM) based hybrid technique for the WEDM parameter optimization to obtain better material removal rate $(0.2704 \mathrm{~g} /$ $\mathrm{min})$ and average surface roughness $(1.3561 \mu \mathrm{m})$ when machining tungsten carbide.

The review of important available literature reveals that hybrid optimization techniques have been found effective to optimize the WEDM parameters to obtain the improved machinability while machining various materials. However, specifically, for WEDM of shape memory alloys type DTM material, there is a lack of work on use of hybrid soft computing techniques for modeling and optimization. The present work fulfils this gap and aims to focus on TOPSIS-Fuzzy-PSO integrated modeling and optimization of wire-EDM of $\mathrm{Ni}_{55.8}$ Ti alloy while simultaneously considering material removal rate (MRR), surface roughness (SR), and recast layer as responses. The experimental, modeling and optimization methodology and the results obtained are presented in the subsequent sections.

\section{EXPERIMENTAL PROCEDURE}

This section details the work-material, experimental set-up, measurement of responses, and experimental planning. The $\mathrm{Ni}_{55.8} \mathrm{Ti}$ raw 
material for wire-EDM was in the form of a cylindrical bar with the diameter of $16 \mathrm{~mm}$ and length of $550 \mathrm{~mm}$. It was cut in circular pieces of $2 \mathrm{~mm}$ thickness while wire-EDM machining. A total of sixteen experiments have been performed as per Taguchi's robust design of experiment technique with $\mathrm{L}_{16}$ orthogonal array. Figure 1 shows the experimental setup used for wire-EDM of $\mathrm{Ni}_{55.8} \mathrm{Ti}$ alloys. Four wire-EDM parameters, namely servo voltage 'SV', pulseon time ' $\mathrm{P}_{\text {on }}$ ', pulse-off time ' $\mathrm{P}_{\text {off }}$ ', wire feed rate 'WF' have been varied at four levels each.
Material removal rate (MRR), maximum roughness $\left(\mathrm{R}_{\mathrm{t}}\right)$, and recast layer thickness $(\mathrm{RCL})$ are the responses measured to evaluate the process productivity and surface quality. Table 1 gives the details of wire-EDM parameters. For the measurement of MRR, the weight difference of material bar (in grams) before and after machining is divided by the machining time (in minutes). Maximum surface roughness $R_{t}$ is the distance between the highest peak and deepest valley and was measured using a TmTech make surface roughness tester

Table 1. Details of wire-EDM parameters

\begin{tabular}{|c|c|c|c|c|c|c|}
\hline \multicolumn{7}{|c|}{ Variable process parameters } \\
\hline $\begin{array}{l}\text { Sr. } \\
\text { No. }\end{array}$ & Machining Parameter & Unit & Level 1 & Level 2 & Level 3 & Level 4 \\
\hline 1 & Spark Gap Voltage 'SV' & Volts & 20 & 30 & 40 & 50 \\
\hline 2 & Pulse-on Time ' $P_{\text {on }}$ ' & $\mu \mathrm{s}$ & 0.35 & 0.55 & 0.8 & 1 \\
\hline 3 & Pulse off-Time ' $P_{\text {off }}$ ' & $\mu \mathrm{s}$ & 9 & 11.5 & 15 & 24 \\
\hline 4 & Wire Feed rate 'WF' & $\mathrm{m} / \mathrm{min}$ & 3 & 6 & 9 & 12 \\
\hline \multicolumn{7}{|c|}{ Constant process parameters } \\
\hline 1 & Dielectric pressure & & \multicolumn{4}{|c|}{$7 \mathrm{~kg} / \mathrm{cm}^{2}$} \\
\hline 2 & Wire tension & & \multicolumn{4}{|c|}{$11.8 \mathrm{~N}$} \\
\hline 3 & Dielectric temperature & & \multicolumn{4}{|c|}{$20-24^{\circ} \mathrm{C}$} \\
\hline 7 & Working temperature & & \multicolumn{4}{|c|}{$25^{\circ} \mathrm{C}$} \\
\hline 5 & Dielectric & & \multicolumn{4}{|c|}{ Deionized water } \\
\hline 6 & Electrode & & \multicolumn{4}{|c|}{ Zinc coated brass wire ( $0.25 \mathrm{~mm}$ diameter $)$} \\
\hline 7 & Work-Piece & & \multicolumn{4}{|c|}{$\mathrm{Ni}_{55.8} \mathrm{Ti} \mathrm{SMA}$} \\
\hline
\end{tabular}

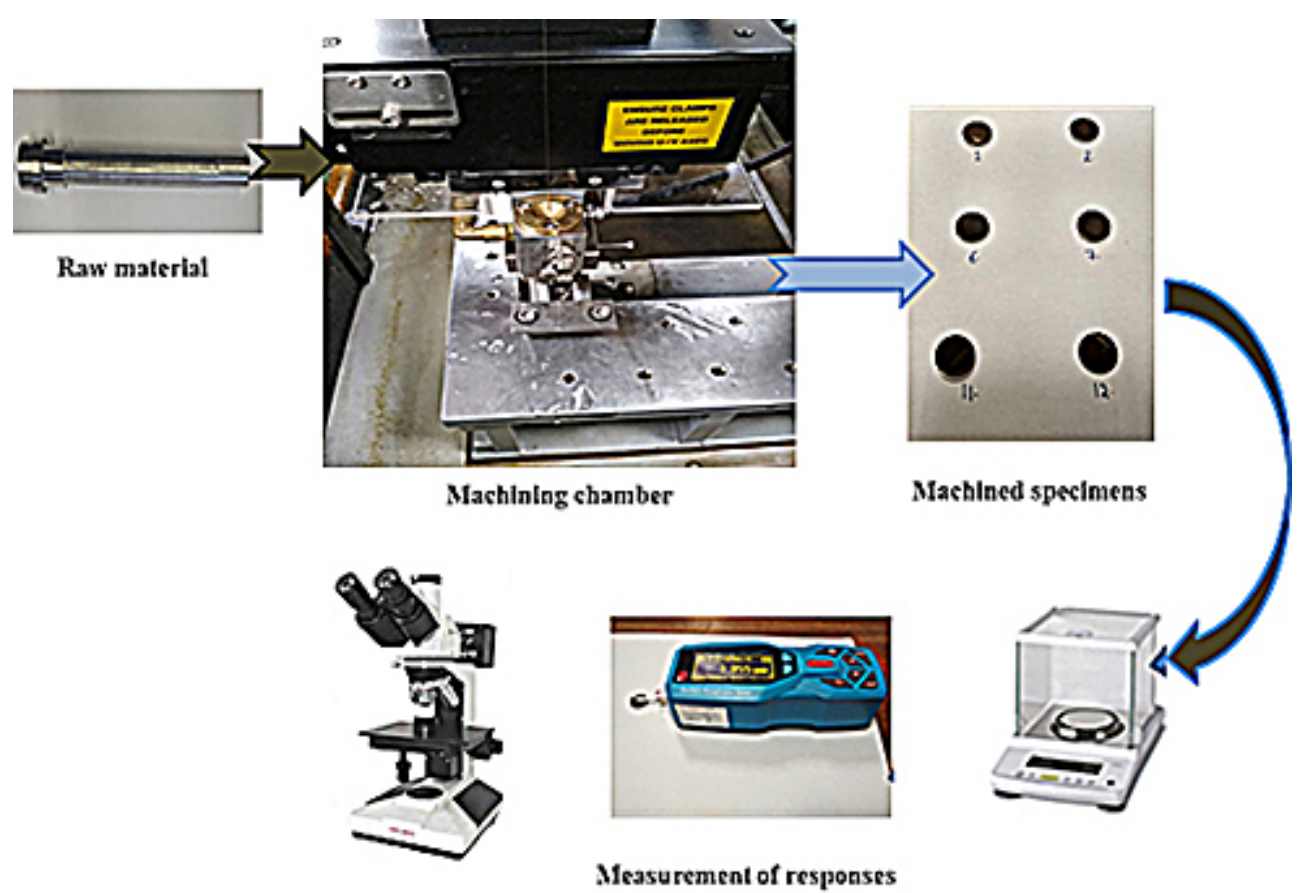

Fig. 1. Experimental setup 
Table 2. Experimental matrix with results

\begin{tabular}{|c|c|c|c|c|c|c|c|}
\hline SI. No. & $\mathrm{SV}$ & $\mathrm{P}_{\text {on }}$ & $\mathrm{P}_{\text {off }}$ & $\mathrm{WF}$ & $\mathrm{MRR}$ & $\mathrm{R}_{\mathrm{t}}$ & $\mathrm{RCL}$ \\
\hline 1 & 20 & 0.35 & 9 & 3 & 0.007 & 8.159 & 8.23 \\
\hline 2 & 20 & 0.5 & 11.5 & 6 & 0.024 & 8.876 & 11.03 \\
\hline 3 & 20 & 0.85 & 15 & 9 & 0.026 & 9.093 & 13.22 \\
\hline 4 & 20 & 1 & 24 & 12 & 0.027 & 9.885 & 16.28 \\
\hline 5 & 30 & 0.35 & 11.5 & 9 & 0.009 & 8.823 & 7.23 \\
\hline 6 & 30 & 0.5 & 9 & 12 & 0.028 & 9.649 & 13.01 \\
\hline 7 & 30 & 0.85 & 24 & 3 & 0.017 & 8.497 & 13.48 \\
\hline 8 & 30 & 1 & 15 & 6 & 0.032 & 10.246 & 17.29 \\
\hline 9 & 40 & 0.35 & 15 & 12 & 0.011 & 8.759 & 9.12 \\
\hline 10 & 40 & 0.5 & 24 & 9 & 0.021 & 9.127 & 10.84 \\
\hline 11 & 40 & 0.85 & 9 & 6 & 0.032 & 9.559 & 16.46 \\
\hline 12 & 40 & 1 & 11.5 & 3 & 0.029 & 10.413 & 18.75 \\
\hline 13 & 50 & 0.35 & 24 & 6 & 0.009 & 8.515 & 9.12 \\
\hline 14 & 50 & 0.5 & 15 & 3 & 0.025 & 8.805 & 13.32 \\
\hline 15 & 50 & 0.85 & 11.5 & 12 & 0.036 & 10.473 & 17.16 \\
\hline 16 & 50 & 1 & 9 & 9 & 0.044 & 11.332 & 21.67 \\
\hline
\end{tabular}

perpendicular to the travel of wire electrode i.e. across the machining direction. Average of the four values was considered as final value. Thickness of the recast layer RCL which is unavoidable as well as undesirable was measured using an optical microscope.

Figure 2 presents the sequence of tasks conducted during intelligent machining of $\mathrm{Ni}_{55.8} \mathrm{Ti}$ by wire-EDM process in the present work. As it was shown, experimental planning and design using Taguchi L16 was followed by the evaluation of performance index using TOPSIS, and thereafter Fuzzy was applied for fuzzification and defuzzification. The regression analysis of TOPSIS Fuzzy performance index was conducted and then PSO was used to predict the optimum setting which was further verified by conducting confirmation experiments.

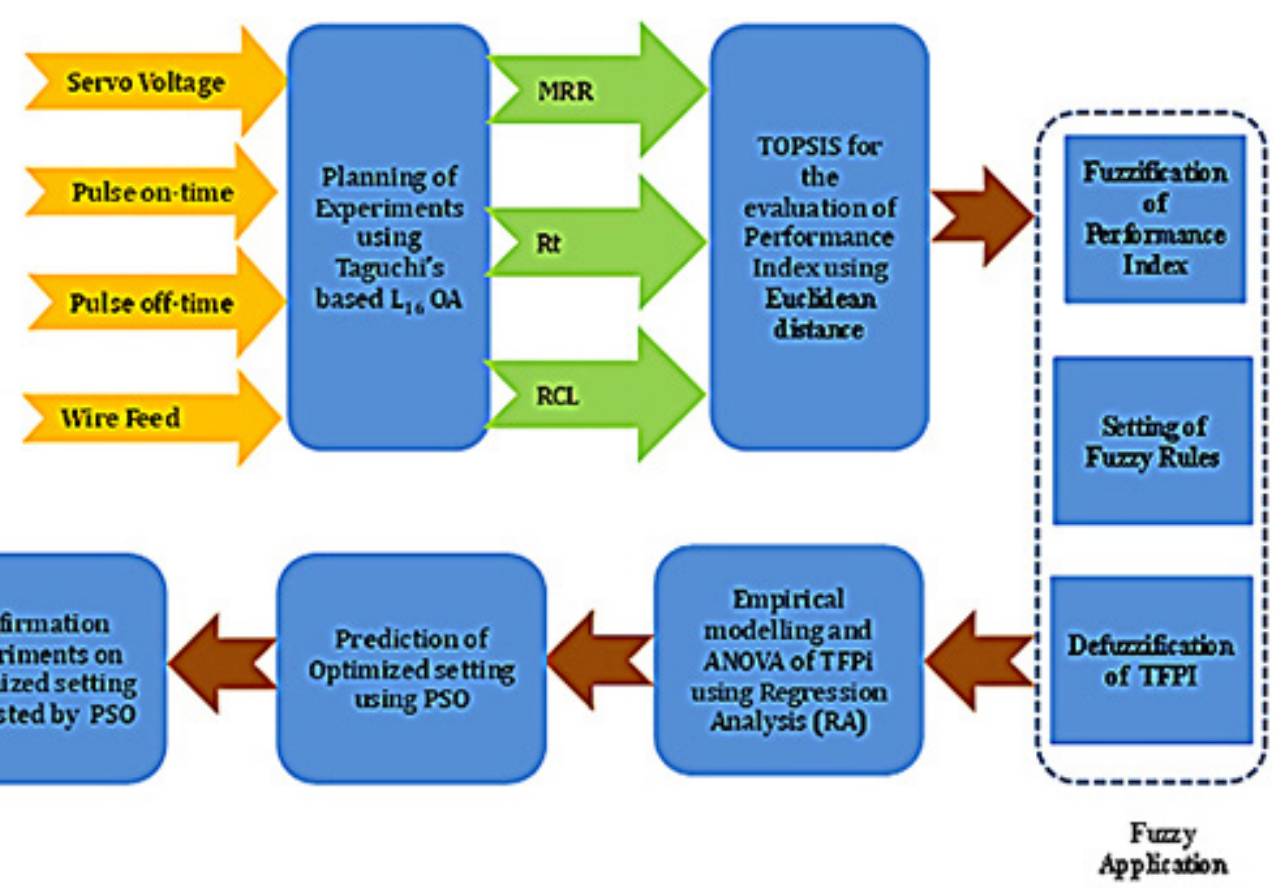

Fig. 2. Sequence of tasks i.e. experimentation-measurement-modelingcomputation performed in the present work 
TOPSIS-Fuzzy is a multi-criteria decision making (MCDM) technique where all responses are converted into one performance index $(\mathrm{Pi})$ and computation of input parameters is done for that performance index. A hybrid technique of TOPSIS-Fuzzy logic was used to compute WEDM parameters for optimization. Data normalization was done using TOPSIS.

\section{RESULTS AND DISCUSSION}

Table 2 presents the experimental matrix i.e. experimental combinations of process parameters and corresponding values of responses. This has been used as a source data for TOPSIS normalization.

\section{Parametric Analysis}

The effects of wire-EDM parameters on the response characteristics (MRR, $R_{t}$ and $R C L$ ) are presented with the help of Figs. 3-5. The variation of MRR with wire-EDM parameters are shown in Fig. 3. It was found that the fourth level of SV, fourth level of $\mathrm{P}_{\text {on }}$, first level of $\mathrm{P}_{\text {off }}$ and fourth level of WF suggest the maximum MRR. Maximum roughness $R_{t}$ is a lower the better type quality characteristic i.e. contrary to the MRR.

Owing to this, the first level of SV, first level of $\mathrm{P}_{\text {on }}$, fo fourth rth level of $\mathrm{P}_{\text {off }}$ and first level of WF correspond to the minimum $\mathrm{R}_{\mathrm{t}}$ (that implies highest surface finish) value as shown in Fig. 4. Fig. 5 illustrates the effect of wire-EDM parameters on RCL. A better surface morphology for the biomedical applications of $\mathrm{Ni}_{55.8}$ Ti alloy requires $\mathrm{RCL}$ thickness as low as possible. Hence, low value of $\mathrm{SV}$ and $\mathrm{P}_{\text {on }}$ along with the high value of $\mathrm{P}_{\text {off }}$ and intermediate value of WF correspond to a machining condition providing least recast layer thickness.

\section{TOPSIS-Fuzzy-PSO Optimization}

After experimentation, the TOPSIS-Fuzzy based hybrid MCDM technique was used to obtain the optimum values of wire-EDM parameters for MRR (higher the better type) and Rt and RCL

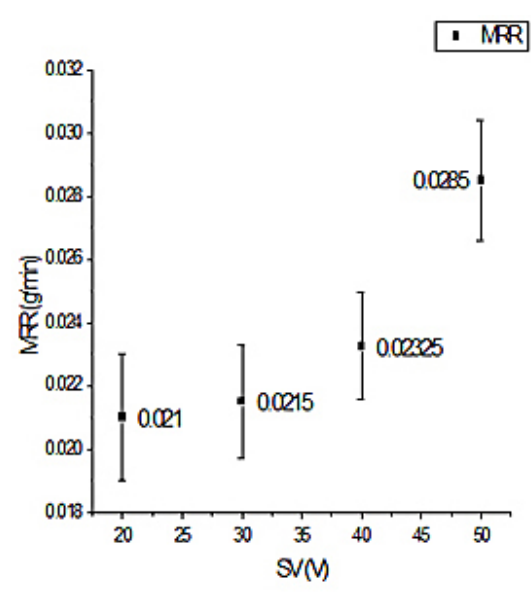

(a) SV versus MRR

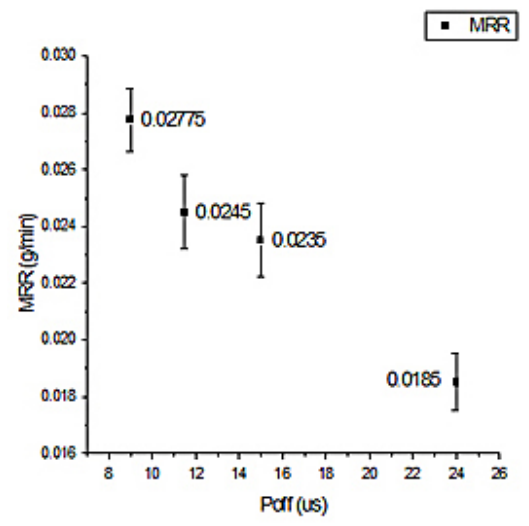

(c) Poff versus MRR

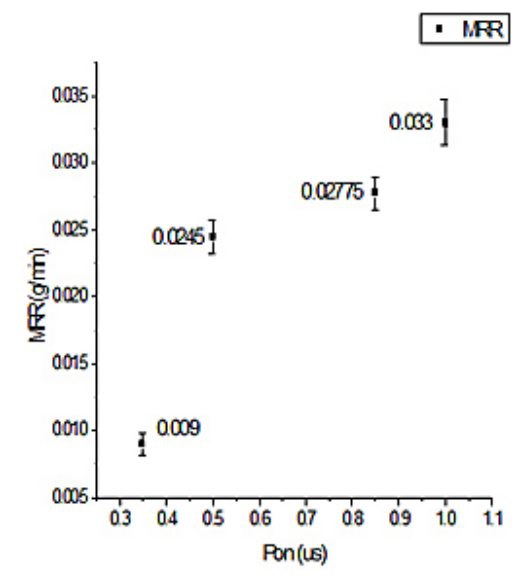

(b) Pon Versus MRR

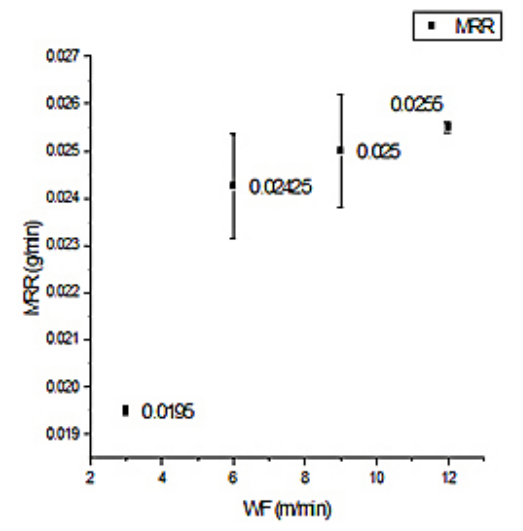

(d) WF versus MRR

Fig. 3. Variation of MRR with respect to input parameters 


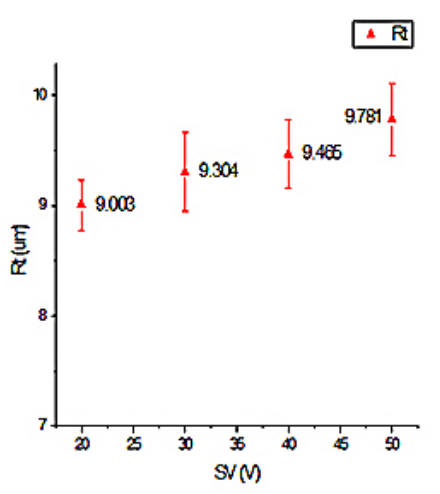

(a) $S V$ versus $R_{t}$

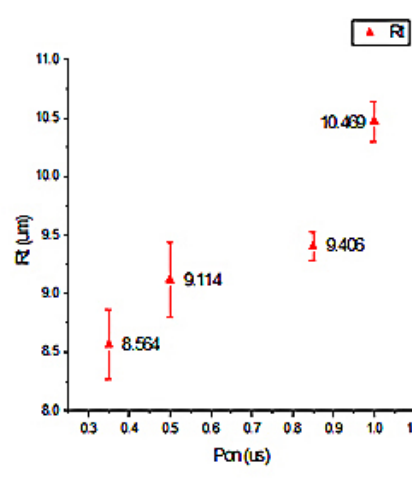

(b) Pon Versus R,

$\Delta \mathrm{Rt}$

$4 \mathrm{R}$
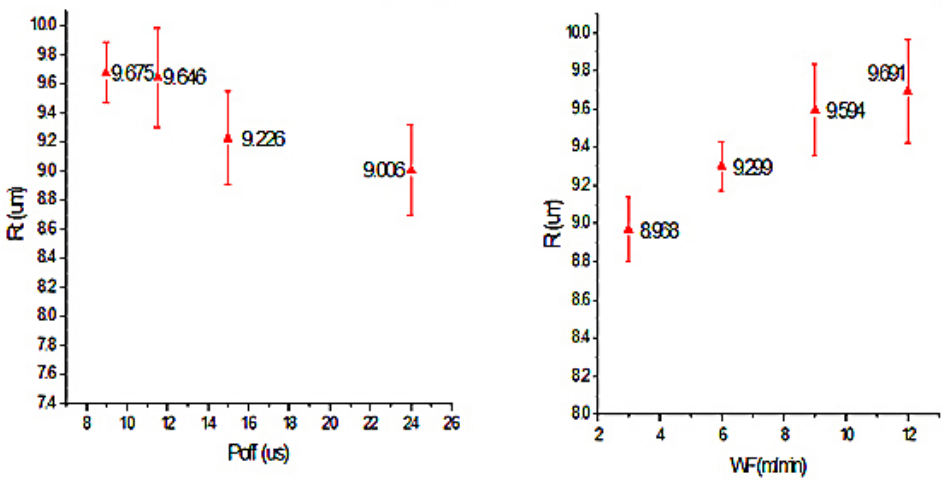

(c) Poff versus $R_{t}$

(d) WF versus $R_{t}$

Fig. 4. Variation of $R_{t}$ with respect to input parameters

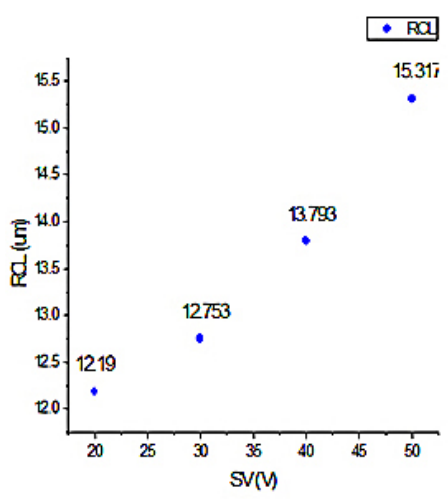

(a) $\mathrm{SV}$ versus RCL

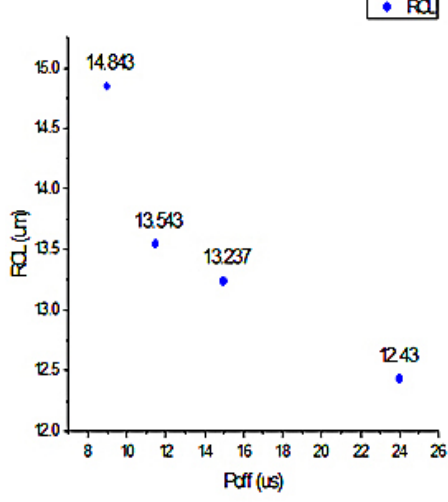

(c) Poff versus RCL

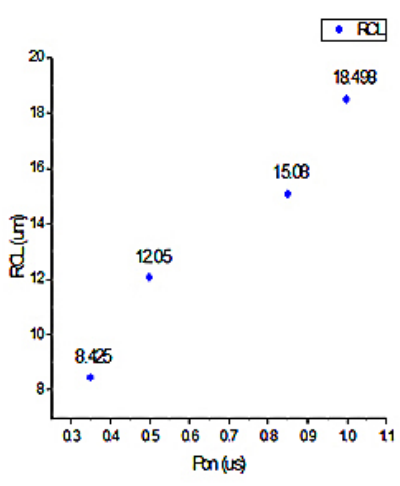

(b) Pon Versus RCL

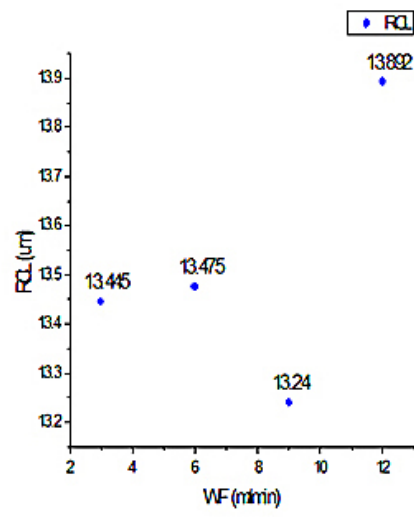

(d) WF versus RCL

Fig. 5. Variation of RCL with respect to input parameters 
(smaller the better) type. After normalization, fuzzification was done, and then a Fuzzy model was developed by Fuzzy interface system (FIS), Mamdani type by a membership function (MF) for input and output parameters.

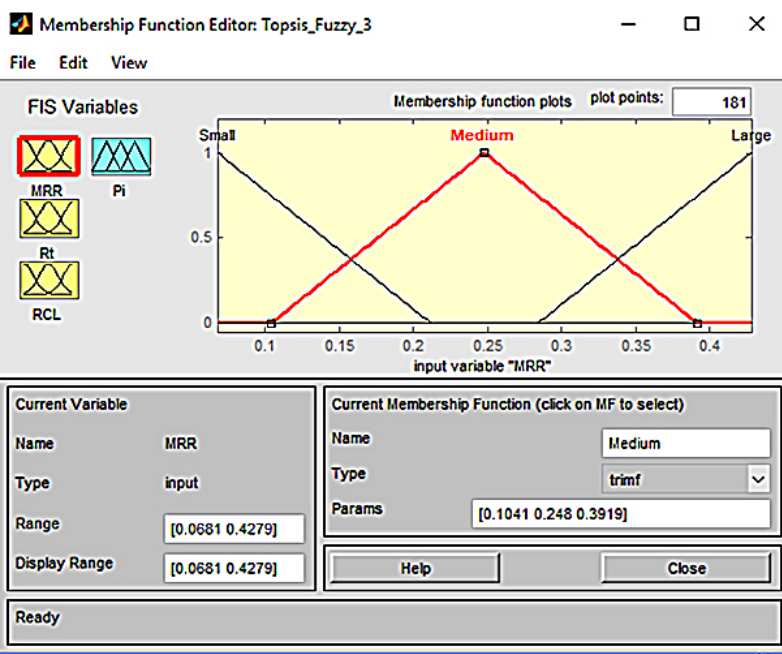

a)

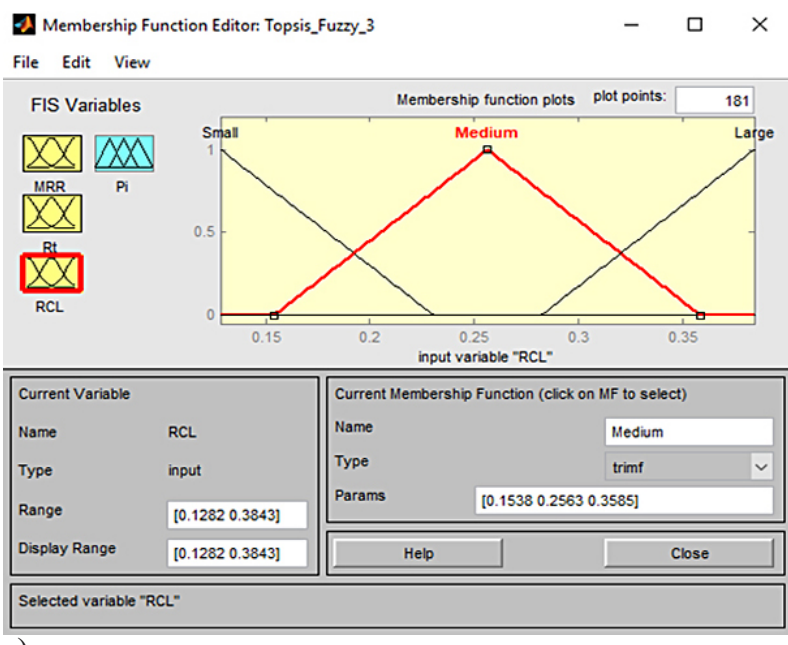

c)

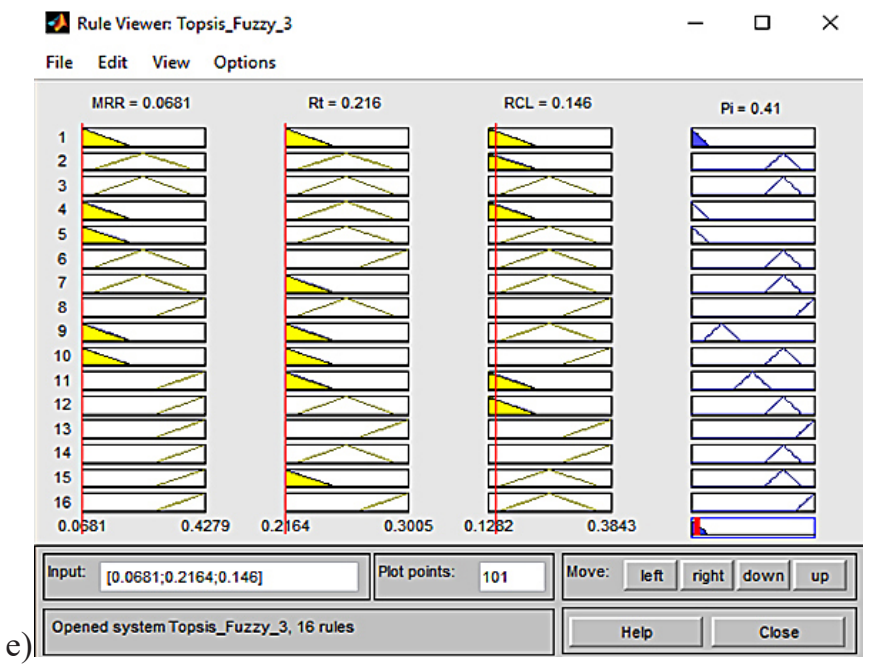

Fig. 6. Fuzzy membership functions for input and outputs with fuzzy rules; a) Membership function for MRR; b) Membership function for $\mathrm{R}_{\mathrm{t}}$; c) Membership function for RCL; d) Membership function for Pi; e) Fuzzy rules

Fig. 6a-c depicts the three level MF for input parameters used in FIS. Fig. 6d shows the five level MF for output parameter. The fuzzy rules were established to obtain TFPI by the use of "if-then" statement. The fuzzy rules used in present work are:

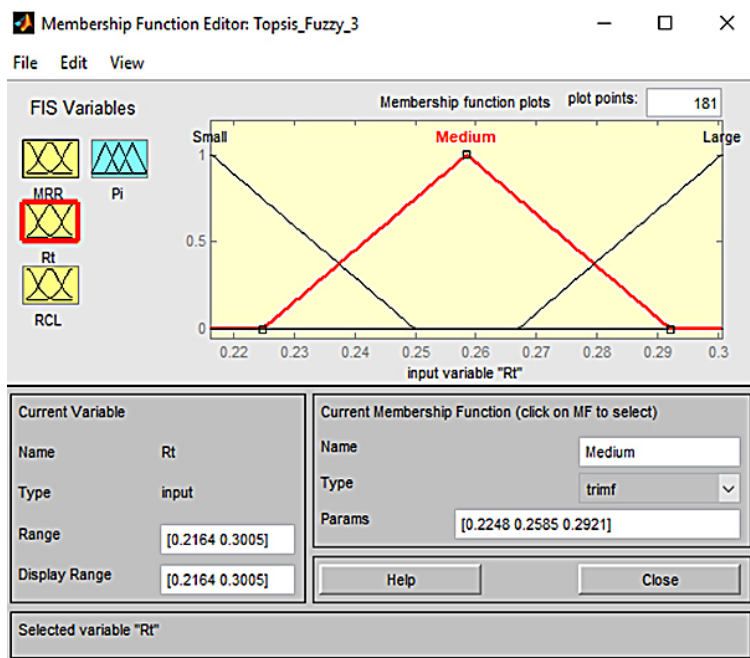

b)
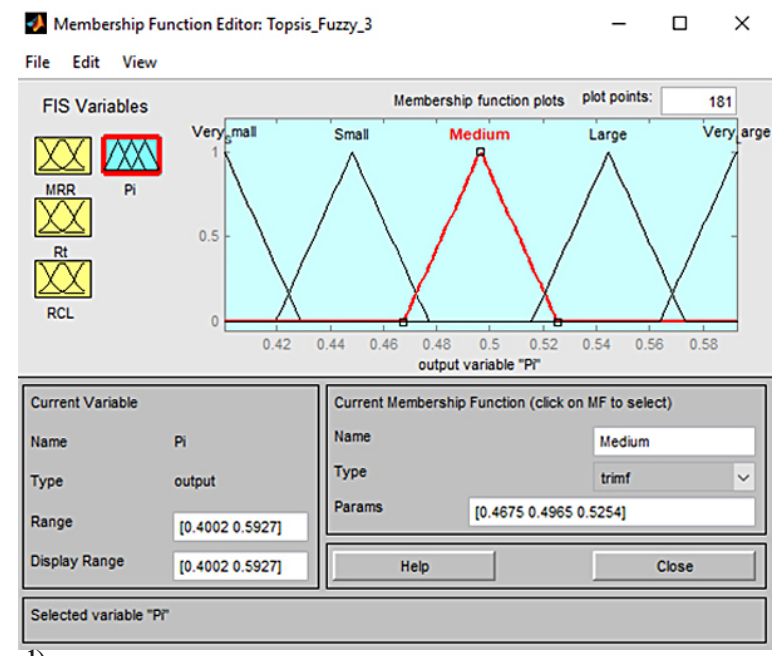

d)

$$
\text { J }
$$

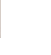


Table 3. TOPSIS normalized and Fuzzy based performance index

\begin{tabular}{|c|c|c|c|c|}
\hline \multirow{2}{*}{ SI. No. } & \multicolumn{3}{|c|}{ Weighted normalized } & TOPSIS-Fuzzy performance index \\
\cline { 2 - 5 } & MRR & $\mathrm{R}_{\mathrm{t}}$ & $\mathrm{RCL}$ & $\mathrm{TFPi}$ \\
\hline 1 & 0.0681 & 0.2164 & 0.1460 & 0.41 \\
\hline 2 & 0.2334 & 0.2354 & 0.1956 & 0.545 \\
\hline 3 & 0.2529 & 0.2411 & 0.2345 & 0.545 \\
\hline 4 & 0.2626 & 0.2622 & 0.2887 & 0.411 \\
\hline 5 & 0.0875 & 0.2340 & 0.1282 & 0.545 \\
\hline 6 & 0.2723 & 0.2559 & 0.2307 & 0.501 \\
\hline 7 & 0.1653 & 0.2253 & 0.2391 & 0.551 \\
\hline 8 & 0.3112 & 0.2717 & 0.3066 & 0.429 \\
\hline 9 & 0.1070 & 0.2323 & 0.1617 & 0.524 \\
\hline 10 & 0.2042 & 0.2420 & 0.1923 & 0.548 \\
\hline 11 & 0.3112 & 0.2535 & 0.2919 & 0.545 \\
\hline 12 & 0.2820 & 0.2762 & 0.3325 & 0.419 \\
\hline 13 & 0.0875 & 0.2258 & 0.1617 & 0.545 \\
\hline 14 & 0.2431 & 0.2335 & 0.2362 & 0.557 \\
\hline 15 & 0.3501 & 0.2777 & 0.3043 & 0.584 \\
\hline 16 & 0.4279 & 0.3005 & 0.3843 & \\
\hline
\end{tabular}

- Rule 1: If MRR is Small and Rt is Small and RCL is Small then TFPI is Very Small.

- Rule 2: If MRR is Medium and Rt is Medium and RCL is Small then TFPI is Large.

- ...

- Rule 16: If MRR is Large and Rt is large and RCL is Medium then TFPI is Very Large.

The performance index evaluated after the defuzzification of supplied normalized input and an output in the form of performance index i.e. TFPi was generated. The values of TFPi, as predicted by hybrid TOPSIS-Fuzzy technique, are shown in Table 3. Figure 6e shows the fuzzy rules used in the present work.

The TFPi value obtained by TOPSIS-Fuzzy was further processed by analysis of variance (ANOVA) to compute the percentage contribution of each wire-EDM process parameters (Table 4). Figure 7 represents the variation of TFPi value with respect to the wire-EDM parameters. As TFPi is larger the better type quality attribute, therefore the better TFPi value is suggested by the highest level of process parameters.

Moreover, the $\mathrm{P}_{\text {on }}$ was found as the most significant parameter. The P-value of all the input parameters is less than 0.05 , which signifies that all the parameters have significant contribution in TFPi. The empirical model corresponding to regression analysis of TFPi is as follows:

$$
\begin{gathered}
\text { TFPi }=0.3915+0.000545 S V+ \\
+0.1645 \text { Pon }-0.00155 \text { Poff }+0.00188 W F^{(1)}
\end{gathered}
$$

The empirical model (Eq. 1) developed by regression analysis is solved by the PSO algorithm. The four input parameters used in the present work were incorporated in Eq. 1 with the lower and upper limits as given from Equations 2-5.

$$
20 \leq S V \leq 50
$$

\begin{tabular}{|c|c|c|c|c|c|c|}
\hline Source & DF & SS & $\begin{array}{l}\text { Percentage } \\
\text { contribution }\end{array}$ & MS & $\mathrm{F}$ & $P$ \\
\hline SV & 3 & 0.001206 & 2.28 & 0.000402 & 30.54 & 0.009 \\
\hline Pon & 3 & 0.049466 & 93.4 & 0.016489 & 1252.30 & 0.000 \\
\hline Poff & 3 & 0.001387 & 2.62 & 0.000462 & 35.13 & 0.008 \\
\hline WF & 3 & 0.000860 & 1.62 & 0.000287 & 21.76 & 0.015 \\
\hline Residual error & 3 & 0.000040 & 0.08 & 0.000013 & & \\
\hline Total & 15 & 0.052959 & \multicolumn{4}{|c|}{$\mathrm{R}^{2}: 99.93 ; \mathrm{R}^{2}$ (adj.): 99.63} \\
\hline
\end{tabular}

Table 4. ANOVA for TFPi 


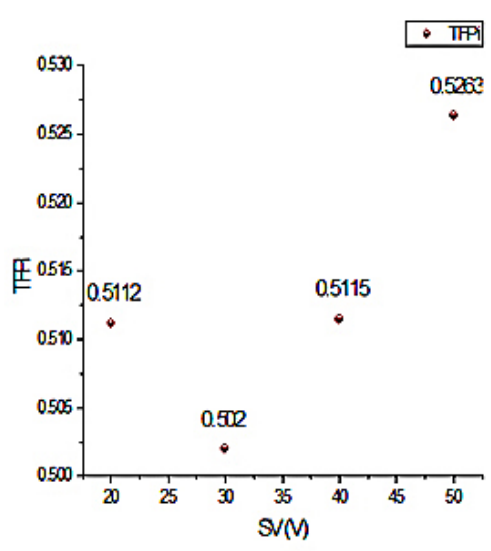

(a) SV versus TFPi

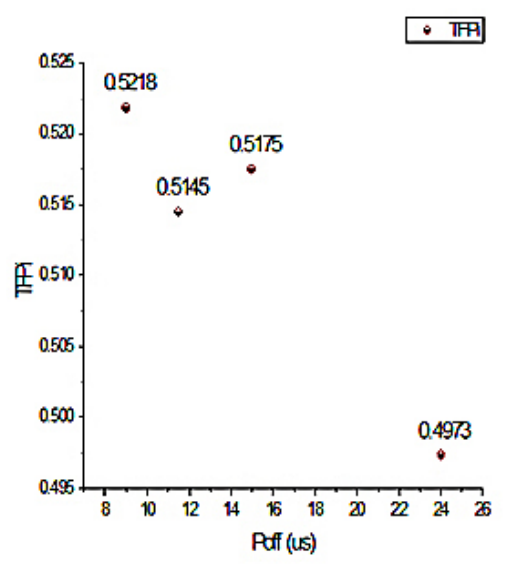

(c) Poff versus TFPi

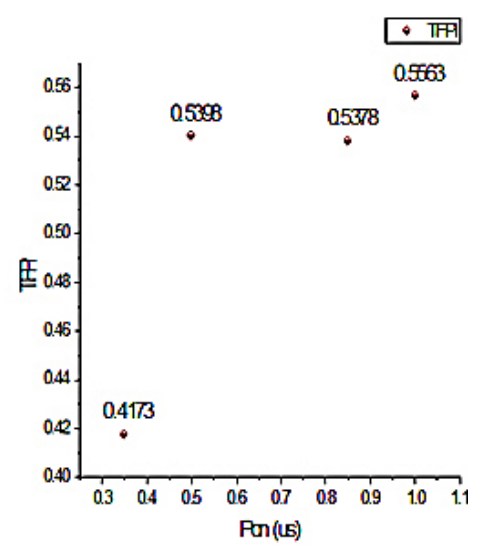

(b) Pon Versus TFPi

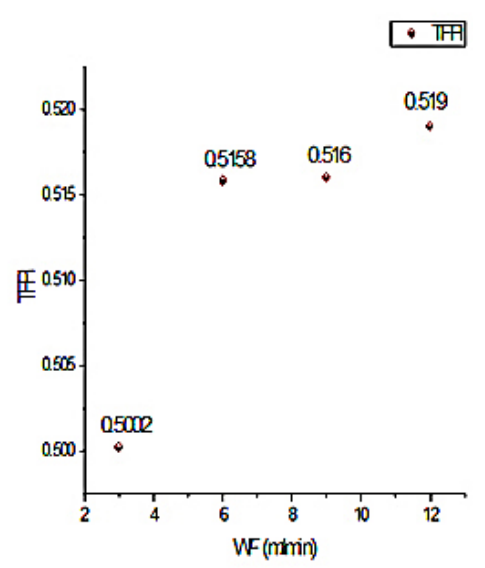

(d) WF versus TFPi

Fig. 7. Variation of TFPi with respect to the input parameters

$$
\begin{gathered}
0.35 \leq \text { Pon } \leq 1 \\
9 \leq \text { Poff } \leq 24 \\
3 \leq W F \leq 9
\end{gathered}
$$

Along with the above limits of input parameters, the values of inertia weight $=0.4$ to 1 ; and acceleration coefficients as $\mathrm{C}_{1}: 1.35, \mathrm{C}_{2}: 2.45$ were used for the calculation of optimized value (TFPi).

Figure 8 illustrates the global best solution for the TFPi with the iteration. The solution was plotted between the objective function (developed by the empirical model) and number of iterations. It was observed that each solution exhibits its own best solution and global best solution was attained after a few iterations. The value of TFPi suggested by PSO algorithm is 0.5631 . The Weibull distribution of probability for TFPi is represented in Figure 9. It was depicted that the probability distribution start at a value of 0.005 corresponding to a probability value of 0.5 and TFPi value of 0.5631 corresponds to a probability of 0.99 . The optimized setting of the process parameters suggested by PSO is SV: $50 \mathrm{~V} ; \mathrm{P}_{\text {on }}: 1 \mu \mathrm{s} ; \mathrm{P}_{\text {off }}: 17 \mu \mathrm{s}$ and WF: 4m/min.

\section{VALIDATION OF RESULTS}

The computed optimum values of wire-EDM parameters by hybrid TOPSIS-Fuzzy-PSO were

Table 5. Validation experiments at optimal settings of process parameters

\begin{tabular}{|c|c|c|c|c|}
\hline SI. No. & Response & $\begin{array}{c}\text { Process parameter setting for } \\
\text { single response optimization }\end{array}$ & $\begin{array}{c}\text { Predicted best value for } \\
\text { single response }\end{array}$ & $\begin{array}{c}\text { Experimental value by TFPi at } \\
{\left[(\mathrm{SV})_{50}\left(\mathrm{P}_{\text {on }}\right)_{1}\left(\mathrm{P}_{\text {off }}\right)_{17}(\mathrm{WF})_{4}\right]}\end{array}$ \\
\hline 1. & TFPi & $(\mathrm{SV})_{50}\left(\mathrm{P}_{\text {on }}\right)_{1}\left(\mathrm{P}_{\text {off }}\right)_{17}(\mathrm{WF})_{4}$ & 0.5631 & 0.5631 \\
\hline 2. & $\mathrm{MRR}$ & $(\mathrm{SV})_{50}\left(\mathrm{P}_{\text {on }}\right)_{1}\left(\mathrm{P}_{\text {off }}\right)_{9}(\mathrm{WF})_{12}$ & 0.044 & 0.049 \\
\hline 3. & $\mathrm{R}_{\mathrm{t}}$ & $(\mathrm{SV})_{20}\left(\mathrm{P}_{\text {on }}\right)_{0.35}\left(\mathrm{P}_{\text {off }}\right)_{24}(\mathrm{WF})_{3}$ & 7.377 & 11.45 \\
\hline 4. & $\mathrm{RCL}$ & $(\mathrm{SV})_{20}\left(\mathrm{P}_{\text {on }}\right)_{0.35}\left(\mathrm{P}_{\text {off }}\right)_{24}(\mathrm{WF})_{9}$ & 5.745 & 22.10 \\
\hline
\end{tabular}




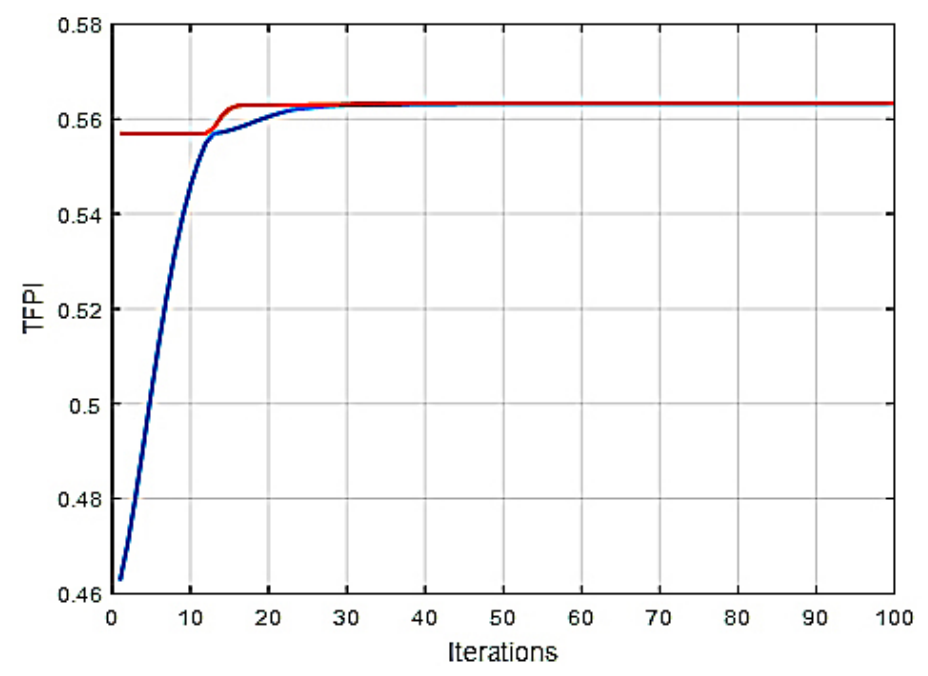

Fig. 8. Global best value of TFPi with the iterations

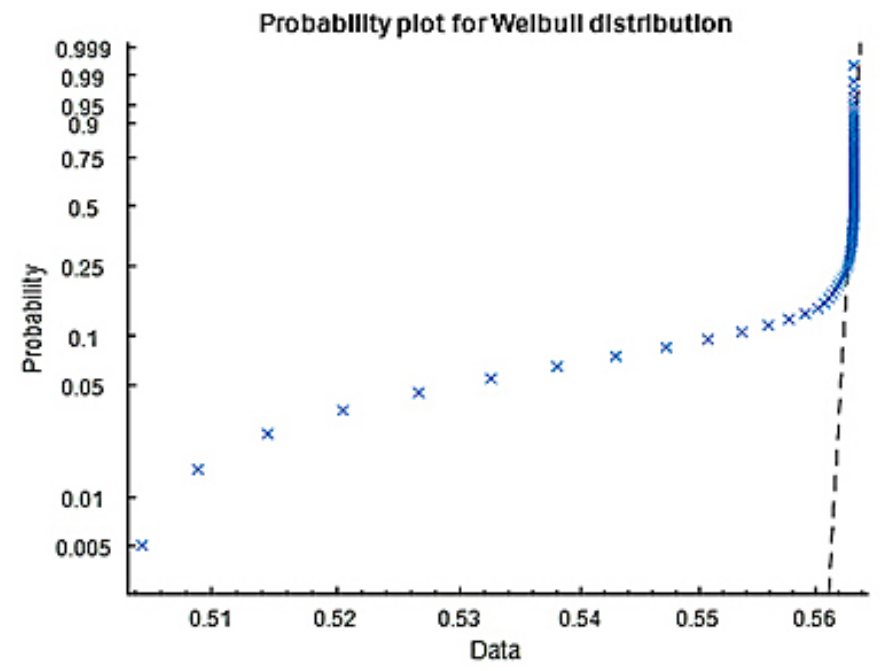

Fig. 9. Probability of the optimized TPFi value

verified by conducting confirmation experiments. As it was seen, the proposed methodology with TOPSIS-Fuzzy-PSO performance index predicts that SV- $50 \mathrm{~V}, \mathrm{P}_{\text {on }}-1 \mu \mathrm{s}, \mathrm{P}_{\text {off }}-17 \mu \mathrm{s}$ and WF- $4 \mathrm{~m} / \mathrm{min}$ as the optimum wire-EDM parameters setting for the best values of responses (See Table 5).

Experiments were conducted at this parameter setting and the responses were measured. It was found that the optimum setting with single set of parameters computed with the help of TFPi (i.e. by the hybrid optimization technique) produced good results, and the actual values of responses are comparable to the predicted values. In the case of $R_{t}$ and RCL, the single response optimization provides better results, but after the implementation of multi-objective optimization a compromise was set and consequently a compromised solution was obtained.
As it was the main objective of this work i.e. to carry out multiperformance/multi-objective optimization in order to obtain the best possible values of all responses together. At this stage, the machine tool was set at the suggested optimal setting and experiments were performed to check the validity of results. Table 5 represents the experimental values of MRR $(0.049 \mathrm{~g} / \mathrm{min})$, $\mathrm{R}_{\mathrm{t}}(11.45 \mu \mathrm{m})$ and RCL $(22.10 \mu \mathrm{m})$ at the optimal setting suggested by TFPi. It was found that at some places, the resultant values suggested by TFPi are comparable to best value, while After investigating the surface morphology of the machined $\mathrm{Ni}_{55.8}$ Ti sample at computed wire-EDM parameters, it was found that optimum machining took place with very small amount of micropores, cracks and other surface defects, making the material significantly useful for biomedical and other precision engineering applications. 


\section{CONCLUSIONS}

TOPSIS-Fuzzy-PSO integrated modeling and computation of process parameters for productivity and surface quality during wire-EDM of $\mathrm{Ni}_{55.8} \mathrm{Ti}$ shape memory alloy was reported in this paper. The following conclusions can be drawn from this work:

1. PSO coupled with fuzzy logic and TOPSIS was successfully used to solve the multi criteria decision making problem and computed optimum set of wire-EDM parameters servo voltage- $50 \mathrm{~V}$, pulse-on time- $1 \mu \mathrm{s}$, pulse-off time- $17 \mu \mathrm{s}$, and wire feed rate- $4 \mathrm{~m} / \mathrm{min}$ for better machining of the $\mathrm{Ni}_{55.8} \mathrm{Ti}$ alloy.

2. ANOVA of TOPSIS-Fuzzy performance index found pulse-on time as the most influencing parameter.

3. PSO algorithm suggests that few numbers of iterations are sufficient to provide the optimized TFPi value rather than huge number of repetitions in statistical techniques. In addition, the optimal setting suggested by PSO provides the optimal setting of input parameters, which lies between two adjacent levels.

4. The proposed TOPSIS-Fuzzy-PSO integrated hybrid technique can also be used further for modeling and optimization of wire-EDM parameters for other responses, such as cutting rate, micro-hardness, and dimensional deviation etc.

\section{REFERENCES}

1. Jani J.M.. Leary M., Subic A., Gibson M.A. A review of shape memory alloy research, applications and opportunities. Materials and Design. 2014;56:1078-1113.

2. Petrini L., Migliavacca F. Biomedical Applications of Shape Memory Alloys. Journal of Metallurgy 2011;501483:1-15 DOI: 10.1155/2011/501483

3. Elahinia M.H., Hashemi M., Tabesh M., Bhaduri S.B. Manufacturing and processing of NiTi implants: A review. Progress in Material Science. 2012;57:911-946.

4. Fabrication and Processing of Shape Memory Alloys, Springer; 2018, ISBN 978-3-319-99306-5.

5. Non-traditional Manufacturing Processes, Marcel Dekker Inc.; 1987, ISBN 0824773527.

6. Khanna K., Singh H. Comparison of optimized settings for cryogenic-treated and normal D-3 steel on
WEDM using grey relational theory. Proceedings of IMechE Part L: Journal of Materials Design and Applications 2016;230:219-232.

7. Zolpakar N.A., Yasak M.F., Pathak S. A review: use of evolutionary algorithm for optimisation of machining parameters. Int J Adv Manuf Technol; 2021.

8. Spavieri G., Ferreira R.T., Fernandes R.A., Lage G.G., Barbosa D., Oleskovicz M. Particle swarm optimization-based approach for parameterization of power capacitor models fed by harmonic voltages. Applied Soft Computing. 2017; 56:55- 64.

9. Choudhuri B., Sen R., Ghosh S.K., Saha S.C. Modelling and multi-response optimization of wire electric discharge machining parameters using response surface methodology and grey-fuzzy algorithm. Proceedings of IMechE. Part B Journal of Engineering Manufacture 2017;231:1760-1774.

10. Caydas U., Hascalik A., Ekici S. An adaptive neuro-fuzzy inference system (ANFIS) model for wire-EDM. Expert Systems with Applications. 2009;36:6135-6139.

11. Singh R., Hussain S.A.L., Dash A., Rai R.N. Modelling and optimizing performance parameters in the wire-electro discharge machining of A15083/B4C composite by multi-objective response surface methodology. Journal of the Brazilian Society of Mechanical Sciences and Engineering. 2020;42:344.

12. Majumder H., Maity K. Prediction and optimization of surface roughness and micro-hardness using grnn and MOORA-fuzzy-a MCDM approach for nitinol in WEDM. Measurement. 2018;118:1-13.

13. Mukherjee R., Chakraborty S., Samanta S. Selection of wire electrical discharge machining process parameters using non-traditional optimization algorithms. Applied Soft Computing. 2012;12:2506-2516.

14. Magabe R., Sharma N., Gupta K., Davim J.P. Modeling and Optimization of Wire-EDM Parameters for Machining of Ni55.8-Ti Shape Memory Alloy using hybrid approach of Taguchi and NSGA-II. The International Journal of Advanced Manufacturing Technology. 2019;102(5): 1703-1717.

15. EI-Bahloul S.A. Optimization of wire electrical discharge machining using statistical methods coupled with artificial intelligence techniques and soft computing. SN Applied Science. 2020;2, Article No. 49.

16. Tzeng C.Z., Yang Y.K., Hsieh M.H., Jeng M.C. Optimization of wire electrical discharge machining of pure tungsten using neural network and response surface methodology. Proceedings of the Institution of Mechanical Engineers, Part B: Journal of Engineering Manufacture. 2011;225(6):841-852. 